\title{
Paulus und die kaiserzeitliche Epistolographie
}

\author{
Kontextualisierung und Analyse der Briefe an Philemon und an die Galater
}

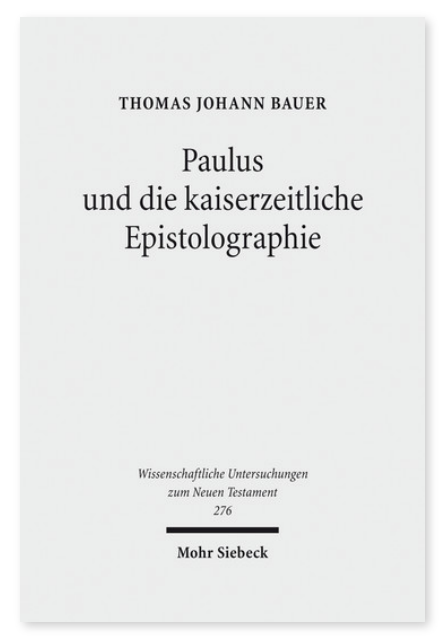

2011. XIII, 482 Seiten. WUNT I 276

ISBN 978-3-16-151775-4

DOI 10.1628/978-3-16-151775-4

eBook PDF 149,00€

ISBN 978-3-16-150977-3

Leinen $149,00 €$
In den Papyrusbriefen kaum gebildeter Absender sozial niederer Herkunft meinte A. Deißmann zu Beginn des 20. Jh. eine Erklärung für die formalen und stilistischen Unterschiede der paulinischen Briefe gegenüber den literarischen Briefen gefunden zu haben. In diesen Unterschieden spiegle sich nicht der semitisch-jüdische Hintergrund der Paulusbriefe, sondern ihre Zugehörigkeit zur nichtliterarischen Gebrauchsprosa. Damit einher ging die Betonung des Gelegenheitscharakters der Paulusbriefe, der sie zum unmittelbaren und ungekünstelten Ausdruck der Person und des religiösen Empfindens ihres Verfassers mache. Gegenüber diesen Positionen, die bis heute in der neutestamentlichen Forschung präsent sind, stellt Thomas Johann Bauer ausgehend von den Briefen an Philemon und an die Galater die Frage, ob die Briefe des Paulus tatsächlich so unliterarisch und kunstlos sind, wie A. Deißmann meinte. Dazu entwickelt er auf der Grundlage der antiken Brieftheorie und im Blick auf die formalen Konventionen und Funktionen des Briefes in der Antike differenzierte Kriterien für die Analyse und Kontextualisierung der paulinischen Briefe. Zusätzlich werden kommunikationstheoretische Überlegungen einbezogen, die in den letzten Jahren in der Klassischen Philologie für die Analyse antiker Briefe nutzbar gemacht wurden und den Blick für die gezielte briefliche Selbstdarstellung des Absenders geschärft haben. Auf der Grundlage dieser methodischen Überlegung entsteht ein Programm, das auch eine nahtlose Integration rhetorischer Aspekte (Argumentation und Ethopoiie) in die Briefanalyse ermöglicht.

Thomas J. Bauer Keine aktuellen Daten verfügbar.

Jetzt bestellen:

https://mohrsiebeck.com/buch/paulus-und-die-kaiserzeitliche-epistolographie-9783161517754?no_cache=1 order@mohrsiebeck.com

Telefon: +49 (0)7071-923-17

Telefax: $+49(0) 7071-51104$ 